\title{
Pengaruh Celebrity Endorser Dan Brand Image Terhadap Keputusan Pembelian Shampoo Clear
}

\author{
Natalia Junni Kalangi \\ Lucky F. Tamengkel \\ Olivia Walangitan

\begin{abstract}
Program Studi Administrasi Bisnis, Jurusan Ilmu Administrasi Fakultas Ilmu Sosial dan Politik, Universitas Sam Ratulangi Manado

Nataliayunikalangi13@gmail.com
\end{abstract}

\begin{abstract}
This study aims to determine: (1) the effect of celebrity endorsement on purchasing decisions for Clear brand shampoo, (2) the effect of brand image on purchasing decisions up to Clear brand, and (3) the influence of celebrity endorse and brand image on Clear shampoo shampoo purchase decisions.This study uses a quantitative approach bycollecting data through survey methods. This study also uses a purposive sampling technique based on certain characteristics. The sample in this study were 100 people of the Wenang subdistrict of Manado city. Data collection techniques using questionnaires that have been tested for validity and reliability. The data analysis technique used to answer the hypothesis is multiple regression.The results of this study indicate that: (1) Celebrity endorse has a positive effect on purchasing decisions, evidenced by the value of $t$ count of 2.186 with a significance value of 0.031 , smaller than 0.05 and the regression coefficient has a positive value of 0.340; (2) Brand image has a positive effect onpurchasing decisions, evidenced from the value of $t$ count of 4.346 with a significance value of 0,000 , smaller than 0.05 and the regression coefficient has a positive value of 0.749, and (3) Celebrity endorsers and brand images have a positive effect against purchasing decisions, as evidenced by the results of $F$ count of 29,446 with a significance of 0,000. The adjusted $R$ square value of 0.378 indicates that the ability of the independent variable in explaining the variation of the dependent variable is $37.80 \%$, and the remaining $62.20 \%$ is explained by other variables outside the research model.
\end{abstract}

Keywords: Celebrity Endorser, Brand Image, Buying Decision

Pendahuluan

Persaingan di dunia bisnis saat inisudah semakin ketat, sehingga menyebkan setiap perusahaan berlombalomba demi mencapai keunggulan kompetitif untuk memperebutkan pangsa pasar. Salah satu industry fast moving customer yang potensial adalah industri toiletris, di mana industri tersebut memproduksi kebutuhan kebersihan sehari-hari oleh konsumen untuk merawat kesehatan dan keindahan rambut. Pemilihan shampo yang tepat akan mendukung kesehatan dan pertumbuhan rambut menjadi lebih baik lagi. Di tengah persaingan produk shampo yang ketat, 
para produsen shampo berlomba-lomba untuk menawarkan produknya yang sesuai dengan kebutuhan dan keinginan konsumen dengan berbagai inovasi dan keunggulan dari masing-masing produk.

Berbagai merek shampo di Indonesia saat ini sedang mencoba untuk bertahan di pasaran karena persaingan yang begitu ketat untuk memperebutkan pasar sasaran. Produsen shampo di Indonesia di kuasai oleh dua perusaan yang sudah di kenal namanya yaitu PT. Unilever Tbk dan PT Procter \& Gamble (P\&G). Produk sampo yang menjadi andalan dari perusahaan Uniliver di antaranya Clear, Sunsilk, Lifebuoy, dan Dove. Sedangkan produk sampo yang menjadi andalan dari perusaan $\mathrm{P} \& \mathrm{G}$ adalah Rejoice, dan Head\&Shoulders, Pantene. Pada Top brand Index Shampo Tahun 2015-2019 peneliti melihat adanya masalah yang terjadi pada tingkat penjualan produk Shampo Clear yang terus megalami penurunan di tahun 2015-2018, Peningkatan jumlah penjualan tertinggi terjadi pada tahun 2015 yaitu sebesar $22,1 \%$. Pertumbuhan terendah penjualan produk clear shampo terjadi pada tahun 2018 yaitu sebesar 17,2\%. Kemudian pada tahu 2019 Clear mengalami kenaikan presentase yang lumayan tinggi yaitu $19,8 \%$, Namun kenaikan tersebut belum mampu menggeser posisi pantene di nomor satu yang menjadi market leader pada periode tersebut.
Untuk mendukung penyampaian iklan, maka di gunakan seorang endorser dalam keberhasilan suatu produk. Strategi periklanan melalui Celebrity endorser juga dilakukan oleh produsen Clear. Produk Clear hadir dengan iklan yang menampiklan Agnes Monica sebagai bintangnya. Namun meskipun Clear sudah menggandeng Agnes Monica sebagai endorsernya namun tetap saja belum mampu menggeser posisi Pantene yang notabenya menggunakan Anggun C Sasmi sebagai endorsernya. Dari personalitas yang terbentuk melalui Celebrity Endorser secara Implicit terbentuk suatu image atau citra atas produk tersebut.

\section{Pemasaran}

Definisi pemasaran telah dikemukakan oleh para ahli pemasaran yang tentunya definisi tersebut bermanfaat bagi organisasi perusahaan untuk dapat memahami arti pemasaran dengan jelas.Seluruh definisi pemasaran yang di kemukakan oleh para ahli, dilatarbelakangi oleh perilaku konsumen yang berbedabeda dan menginginkan kebutuhannya terpenuhi. Seperti yang dikemukakan oleh Jerome (1993:3) bahwa Marketing should begin with potential costumer need with the production process. Maksud dari konsep pemikiran ini adalah, bahwa pemasaran pada dasarnya harus dimulai dar melihat apa yang dibutuhkan oleh konsumen dan disesuaikan dengan proses produksi perusahaan. Sedangkan menurut 
(Schoel \& Guiltinan 1993 :123)

Pengertian pemasaran ini hampir serupa dengan apa yang di kemukakan oleh bahwa perusahaan melaui proses produksi untuk memenuhi kebutuhan dan kepuasan konsumen.

Manajemen pemasaran adalah analisis perencanaan, implementasi dan pengendalian program-program yang di rancang untuk menciptakan, membangun, dan mempertahankan pertukaran yang menguntungkan dengan tingkat pembeli untuk mencapai objektivitas organisasi Kotler \& Amstrong (2007).

\section{Celebrity Endorse}

Celebrity endorse adalah seorang artis, entertainer, atlet, dan public figure yang mana banyak diketahui oleh banyak orang untuk keberhasilan produk yang di dukung (Shimp, 2003). Indikator Celebrity Endorser: Daya Tarik, Kepercayaan, dan Keahlian. Celebrity endorser di definisikan sebagai figure seorang tokoh yang di kenal baik oleh publik dan memperagakan sebagai konsumen dalam ikalan(Belch \& Belch, 2004). Termasuk kelompok selebriti ini adalah bintang televise maupun bintang film, bintang olah raga, politikus, bisnisman, artis, dan orangorang tertentu yang berasal dari militer.

\section{Brand Image}

Citra merek merupakan representase dari keseluruhan persepsi terhadap merek dan di bentuk dari informasi dan pengalaman masa lalu terhadap merek itu (Setiadi, 2003).

Indikator Brand Image: Kekuatan, Keunikan, Keunggulan.

\section{Keputusan pembelian}

Keputusan pembelian merupakan proses dalam pembelian nyata setelah melalui tahap-tahap tertentu. Setelah melakukan evaluasi atas sejumlah alternatif maka pelanggan dapat memutuskan apakah suatu produk akan dibeli atau di putuskan untuk tidak dibeli sama sekali (Stanton, 1997).

Indikator Keputusan Pembelian: Keputusan tentang merek, Keputusan pembelian dari siapa (pemasok), Keputusan tentang jumlah produk yang akan dibeli, Keputusan waktu membeli, Keputusan dalam cara pembayaran.

\section{Metode Penelitian}

Penelitian ini menggunakan pendekatan kuantitatif dengan pengumpulan data melalui metode suvey. Penelitian ini juga menggunakan teknik purposive samling atau pengambilan sampel berdasarkan karakteristik tertentu. Sampel dalam penelitian ini adalah 100 orang masyarakat kecamatan wenang kota kota manado. Teknik pengumpulan data menggunakan kuesioner yang telah di uji Validitas dan Reliabilitasnya. Teknik analisis data yang di gunakan untuk menjawab hipotesis adalah regresi berganda. 


\section{Uji Coba Instrumen}

Agar data yang diperoleh dengan cara menyebarkan kuesioner dapat dianggap valid dan reliabel, maka perlu dilakukan uji validitas dan reliabilitas kuesioner terhadap butir - butir pertanyaan dalam kuesioner.

1. Uji Validitas

Validitas digunakan untuk mengukur sah atau tidaknya suatu kuesioner. Suatu kuesioner dinyatakan valid jika pertanyaan pada kuesioner mampu mengungkapkan sesuatu yang akan diukur oleh kuesioner tersebut. Uji validitas pada penelitian ini dilakukan dengan menggunakan teknik analisis faktor dari program SPSS versi 23.0 forwindows. Teknik analisis faktor yang digunakan untuk menguji adalah Confirmatory Faktor Analysis (CFA).Metode rotasi faktor yang digunakan adalah varimax. Validitas korelasi antar variabel dalam melihat uji Kaiser-Meyer-Olkin Measure of Sampling Adequacy (KMO MSA). Indikator/item pernyataan dinyatakan valid jika korelasi dari masing-masing item terhadap jumlah skor total untuk masing-masing pernyataan untuk variabel X1, X2,dan Y, seluruhnya menghasilkan tingkat koefisien $>0,30$ dan nilai signifikansi $<0,005$.

\section{Uji Reliabilitas}

Instrumen dikatakan reliable
apabila instrument tersebut mampu
mengungkapkan data yang bisa dipercaya

dan sesuai dengan kenyataan sebenarnya. Reliabilitas menunjukkan pada satu pengertian bahwa instrumen cukup dapat dipercaya untuk digunakan sebagai alat pengumpulan data karena instrumen sudah baik (Arikunto, 2006). Uji reliabilitas pada penelitian ini menggunakan model cronbach alpha untuk menentukan apakah setiap instrument reliabel atau tidak. Variabel penelitian dikatakan reliabel jika variabel tersebut memiliki nilai alpha cronbach $>0,60$.

\section{Teknik Analisis Data}

Dalam menganalisis data penelitian ini, peneliti menggunakan teknik Analisis Regresi Linear Berganda. Sebelum dilakukan analisis regresi, terlebih dahulu dilakukan uji asumsi klasik yang terdiri dari uji normalitas, uji multikolinieritas, dan uji heteroskedasitas. Apabila uji asumsi klasik terpenuhi, maka analisis regresi bisa dilakukan:

\section{Uji Asumsi Klasik}

1. Uji normalitas

Pengujian normalitas dilakukan dengan Uji Kolmogorov-Smirnov yang dilakukan terhadap data residual model regresi. Berdasarkan pada titik-titik variabel yang berada di sekitar garis $\mathrm{Y}=\mathrm{X}$ atau menyebar di sekitar garis diagonal serta penyebarannya mengikuti arah garis diagonal, ini menunjukkan bahwa data telah terdistribusi normal. 
a. Uji Multikolinieritas

Ujimultikolinieritas bertujuan untuk menguji apakah model regresi ditemukan adanya korelasi antar variabel independen. Model regresi yang baik seharusnya tidak terjadi korelasi di antara variabel independen. Jika variabel independen saling berkolersai, maka variabel-variabel ini tidak ortogonal. Variabel ortogonal adalah variabel independen yang nilai korelasinya antar sesame variabel independen sama dengan nol.

Untuk mendeteksi ada tidaknya multikolonieritas dapat dilihat dari nilai Tolerance dan lawannya Variance Inflation Factor (VIF). Nilai yang umum dipakai untuk menunjukan adanya multikolonieritas adalah nilai Tolerance $\leq$ 0,10 atau sama dengan nilai $F \geq 10$ (Ghozali, 2011). Uji multikolinieritas diatas dapat dilakukan dengan bantuan komputer menggunakan program aplikasi pengolah data SPSS.

b. Uji Heteroskedastisitas

Uji ini dilakukan untuk mengetahui terjadinya perbedaan ragam residual suatu periode pengamatan ke periode pengamatan yang lain, atau gambaran hubungan antara nilai tang diprediksi dengan Studentized Delete Residual. Cara memprediksi ada tidaknya heteroskedastisitas pada model regresi dapat dilihat pada pola gambar Scatterplot (Nugroho, 2005). Analisis gambar
Scatterplot yang menyatakan tidak terdapat heteroskedastisitas jika :

a. Titik-titik data menyebar diatas dan dibawah atau disekitar angka 0 .

b. Titik-titik data tidak mengumpul hanya diatas atau dibawah saja.

c. Penyebaran titik-titik data boleh membentuk pola.

\section{Analisis Regresi Linear Berganda}

Analisis regresi linear berganda digunakan untuk mengetahui ada tidaknya pengaruh antara Celebrity Edorser dan Brand Image Terhadap Keputusan Pembelian.

\section{Hasil Penelitian}

Analisa Data

a. Uji validitas

\begin{tabular}{lllll} 
& Item & $\begin{array}{l}\text { Pearson } \\
\text { corr }\end{array}$ & $\begin{array}{l}\text { Nilai } \\
\text { signifikan }\end{array}$ & Ket \\
\hline $\mathrm{X} 1=$ & & & & \\
\hline & & 0,795 & 0,000 & VALID \\
$\begin{array}{l}\text { Celberity } \\
\text { Endorse }\end{array}$ & $\mathrm{X} 1.1$ & & & \\
\hline & $\mathrm{X} 1.2$ & 0,717 & 0,000 & VALID \\
\hline $\mathrm{X} 1.3$ & 0,747 & 0,000 & VALID \\
\hline $\mathrm{X} 1.4$ & 0,849 & 0,000 & VALID \\
\hline $\mathrm{X} 1.5$ & 0,772 & 0,000 & VALID \\
\hline $\mathrm{X} 1.6$ & 0,777 & 0,000 & VALID \\
\hline
\end{tabular}

\begin{tabular}{|c|c|c|c|c|}
\hline \multicolumn{5}{|l|}{$\mathrm{X} 2=$} \\
\hline Brand & & 0,730 & 0,000 & VALID \\
\hline \multirow[t]{6}{*}{ Image } & $\mathrm{X} 2.1$ & & & \\
\hline & $\mathrm{X} 2.2$ & 0,767 & 0,000 & VALID \\
\hline & $\mathrm{X} 2.3$ & 0,692 & 0,000 & VALID \\
\hline & $\mathrm{X} 2.4$ & 0,671 & 0,000 & VALID \\
\hline & $\mathrm{X} 2.5$ & 0,804 & 0,000 & VALID \\
\hline & $\mathrm{X} 2.6$ & 0,816 & 0,000 & VALID \\
\hline $\mathrm{Y}$ & & 0,760 & 0,000 & VALID \\
\hline \multicolumn{5}{|l|}{ KEPUT } \\
\hline USAN & Y1.1 & & & \\
\hline \multirow{6}{*}{ LIAN } & & 0,768 & 0,000 & VALID \\
\hline & $\mathrm{Y} 1.2$ & & & \\
\hline & Y1.3 & 0,767 & 0,000 & VALID \\
\hline & Y1.4 & 0,761 & 0,000 & VALID \\
\hline & Y1.5 & 0,691 & 0,000 & VALID \\
\hline & Y1.6 & 0,640 & 0,000 & VALID \\
\hline
\end{tabular}




$$
Y=9,917+0,340+0,749+e
$$

\section{Koefisien Determinasi $\left(\mathbf{R}^{2}\right)$}

Diperoleh nilai koefisien determinasi

Di peroleh hasil yakni, seluruh pernyatan kuesioner baik itu pada variabel independen dan variabel dependen dinyatakan valid. Dapat di katakana valid karena seluruh nilai T-hitung lebih besar dari nilai T-tabel.

\section{b. Uji Reliabilitas}

\begin{tabular}{ccc} 
Nama variabel & koefisien alpha & keterangan \\
\hline $\mathrm{X} 1$ & 0,869 & Reliabel \\
\hline $\mathrm{X} 2$ & 0,840 & Reliabel \\
\hline $\mathrm{Y}$ & 0,873 & Reliabel \\
\hline
\end{tabular}

Dari hasil uji reliabilitas nilai Cronbach's Alpha dari variabel Celebrity Endorser adalah 0,869 atau di atas 0,6 sehingga dapat dikatakan reliabel, lalu nilai Cronbach's Alpha dari variabel Brand Image adalah 0,840 atau diatas 0,6 sehingga dapat dikatakan reliabel dan nilai Cronbach's Alpha dari variabel Keputusan Pembelian adalah 0,873 atau diatas 0,6 sehingga dapat dikatakan reliabel.

\section{Analisis Regresi Linear Berganda}

Berdasarkan hasil pengolahan data. Output dari analisis regresi linear berganda di peroleh persamaan regresi sebagai berikut; adjusted $\mathrm{R}$ square sebesar 0,378 sehingga dapat dinyatakan bahwa terdapat hubungan yang bersifat pengaruh antara Celebrity Endorse dan Brand Imageterhadap Keputusan. Koefisien determinasi sebesar $37,80 \%$ variasi dari Keputusan Pembelian dapat dijelaskan oleh model regresi ini, sedangkan sisanya sebesar $62,20 \%$ dijelaskan oleh variabel

\section{Pembahasan}

\section{Pengaruh Celebrity Endorser terhadap Keputusan Pembelian}

Berdasarkan hasil uji statistik yang telah dilakukan menunjukkan adanya pengaruh positif celebrity endorser terhadap keputusan pembelian sampo merek Clear. Hal ini diperoleh dari hasil statistik uji regresi dengan nilai t hitung sebesar 2,186 dengan nilai signifikansi sebesar 0,031 lebih kecil dari 0,05 $(0,030<0,05)$, dan koefisien regresi mempunyai nilai positif sebesar 0,340 ; maka hipotesis pertama dalam penelitian ini terbukti yaitu "Celebrity Endorser berpengaruh positif terhadap Keputusan Pembelian sampo merek Clear". lain di luar penelitian. 


\section{Pengaruh Brand Image terhadap}

\section{Keputusan Pembelian}

Berdasarkan hasil uji statistik yang telah dilakukan menunjukkan adanya pengaruh positif brand image terhadap keputusan pembelian sampo merek Clear. Hal ini diperoleh dari hasil statistik uji regresi dengan nilai t hitung sebesar 4,346 dengan nilai signifikansi sebesar 0,000 lebih kecil dari $0,05(0,000<0,05)$, dan koefisien regresi mempunyai nilai positif sebesar 0,749; maka hipotesis kedua dalam penelitian ini terbukti yaitu "Brand Image berpengaruh positif terhadap Keputusan Pembelian sampo merek Clear".

\section{Pengaruh Celebrity Endorser dan}

\section{Brand Image terhadap Keputusan}

\section{Pembelian}

Berdasarkan hasil uji statistik yang telah dilakukan menunjukkan adanya pengaruh positif celebrity endorser dan brand image terhadap keputusan pembelian sampo merek Clear. Hal ini diperoleh dari hasil uji $\mathrm{F}$ diperoleh nilai $\mathrm{F}$ hitung sebesar 29,446 dengan signifikansi sebesar 0,000. Oleh karena nilai signifikansi lebih kecil dari 0,05 $(0,000<0,05)$, maka dapat disimpulkan bahwa hipotesis ketiga dalam penelitian ini terbukti yaitu "Celebrity Endorser dan Brand Image secara simultan berpengaruh terhadap Keputusan Pembelian sampo merek Clear". Jadi berdasarkan uji T yang ditabel 8 dapat diketaui bahwa variabel Brand Image $\left(\mathrm{X}_{2}\right)$ mempunyai pengaruh yang lebih dominan terhadap varibel Keputusan Pembelian (Y) karena t hitung yang diperoleh lebih besar di bandingkan variabel Celebrity Endorser $\left(\mathrm{X}_{1}\right)$. Variabel Brand Image lebih dominan dikarenakan keputusan pembelian juga dapat dipengaruhi oleh aspek sebuah merek diantaranya kekuatan, keunikan, keunggulan (Kotler dan Keller, 2003).

Dengan hasil penelitian diatas maka peneliti mengambil kesimpulan bahwa citra merek mengambil peran penting dalam menumbuhkan kepuasan pembelian produk Shampo Clear. Hasil penelitian ini didukung oleh penelitian sebelumnya yang dilakukan oleh Sagita (2013), Musay (2013), Angio (2013), Restiawan (2015) dan Simbolon (2015) bahwa citra merek memiliki pengaruh yang kuat dan signifikan terhadap keputusan pembelian konsumen. Hasil dari penelitian ini juga didukung oleh pendapat para ahli yang menyatakan bahwa citra merek memiliki pengaruh yang signifikan terhadap keputusan pembelian.Richardson, (1994) dalam jurnal Gilaninia dan Mousavian (2012:7549) menyatakan bahwa citra merek sering digunakan sebagai syarat 
ekstrinsik untuk membuat sebuah keputusan pembelian.

Jika konsumen tidak memiliki pengalaman terhadap suatu produk, mereka cenderung untuk mempercayai merek yang disukai atau terkenal (Schiffman dan Kanuuk, 2008).Sebuah merek yang memiliki citra yang positif atau disukai dianggap dapat mengurangi resiko pembelian.Seringkali menggunakan citra merek sebuah produk sebagai salah satu acuan dalam membuat sebuah keputusan pembelian.Itulah sebabnya kenapa variabel Brand Image lebih dominan dari pada variabel Celebrity Endorser.

Namun tingkat pengaruh kedua variabel ini terhadap keputusan pembelian di katakan sedang di lihat dari tabel 10 Pedoman Interprestasi Tinggi Rendahnya Koefisien Determinasi. Karena koefisien determinasinya hanya 0,378 atau $37,80 \%$ variasi dari Keputusan Pembelian dapat dijelaskan oleh model regresi ini, sedangkan sisanya sebesar 62,20\% dijelaskan oleh variabel lain di luar penelitian.

Faktor lain yang mempengaruhi keputusan pembelian yaitu :

$\underline{\text { Harga }}$

Strategi harga sebuah produk ditentukan oleh tingkat kualitas yang diinginkan sebuah perusahaan (Kotler
2009). Harga produk yang ditetapkan oleh perusahaan dapat saja sama atau berbeda dengan produk pesaing yang berada pada segmen yang berbeda pula. Keputusan harga memiliki peran strategis yang penting dalam implementasi strategi pemasaran.Persepsi kualitas sebuah produk oleh konsumen juga dipengaruhi tinggi rendahnya harga yang ditetapkan. Kecenderungan sikap konsumen ini dapat dilihat ketika dihadapkan pada dua pilihan produk yang berbeda harga.Harga produk yang lebih tinggi dipersepsikan secara sederhana memiliki kualitas yang lebih baik dari yang lebih murah.

$\underline{\text { Kualitas Produk }}$

Kualitas produk merupakan apresiasi yang diberikan konsumen pada sebuah produk saat sebelum membeli maupun sesudah menggunakannya (Angipora 2002). Konsumen yang merasa puas, akan kembali membeli dan mereka akan menceritakan pengalamannya dengan orang lain tentang keunggulan sekaligus kekurangan produk yang digunakan. Dampak kualitas terhadap pangsa pasar biasanya bergantung pada definisi tentang kualitas. Jika kualitas didefiniskan sebagai keandalan, estetika tinggi (bagaimana produk terlihat atau terasakan) atau konformansi (tingkat dimana produk memenuhi standar yang ditentukan) maka 
hubungannya dengan pangsa pasar adalah positif.

$\underline{\text { Place }}$

Place atau distribusi (tempat) merupakan faktor penentu keberhasilan pemasaran. Distribusi merupakan sarana sebuah produk untuk memenuhi permintaan produk agar dapat di distribusikan kepada konsumen. Place pada penelitian ini diartikan sebagai dealer atau show room yang berfungsi sebagai saluran distribusi. Distribusi juga dapat diartikan sebagai segala kegiatan yang dilakukan oleh produsen agar produk yang dihasilkan sampai kepada konsumen Strategi yang digunakan oleh perusahaan dalam menawarkan produknya agar menarik minat beli konsumen terhadap produk tersebut adalah melalui iklan. Kesukaan audience pada sebuah iklan tidak lepas dari pendukung iklan itu sendiri yaitu model (endorser). Sebuah perusahaan yang mengiklankan produknya dengan menggunakan dukungan selebritis mencoba mencocokkan image produk dengan kepribadian ataupun fisik endorser yang dipilih. Penggunaan endorser diharapkan dapat memberikan asosiasi positif antara produk dengan endorser. Asosiasi tersebut secara sederhana dapat muncul dalam bentuk pemikiran atau citra tertentu yang dikaitkan pada suatu merek. Keterkaitan pada suatu merek akan lebih kuat apabila dilandasi pada banyak pengalaman untuk mengkomunikasikannya. Berbagai asosiasi yang diingat konsumen dapat dirangkai sehingga membentuk citra tentang merek di dalam benak konsumen. Citra yang baik merupakan salah satu cara yang efektif di dalam menjaring konsumen, karena konsumen dengan sadar atau tidak sadar akan memilih suatu produk yang memiliki brand image yang positif, sehingga tercipta persepsi yang baik di mata konsumen, dan akan mempengaruhi keputusan pembelian konsumen.

\section{Kesimpulan}

Berdasarkan hasil uji pada variabel Celebrity endorser secara parsial berpengaruh signifikan terhadap Keputusan pembelian Shampo Clear.

Berdasarkan hasil uji pada variabel Brand Image secara parsial berpengaruh secara signifikan terhadap Keputusan Pembelian Shampo Clear.

Berdasarkan hasil uji secara simultan dapat di simpulkan bahwa Ha diterima dan H0 ditolak.Artinya kedua variabel independen yaitu Celebrity Endorser dan Brand Image bersama-sama Simultan berpengaruh terhadap variabel Celebrity Endorser 


\section{Saran}

Hasil penelitian ini menunjukan bahwa Celebrity endorser berpengaruh positif terhadap keputusan pembelian. Oleh karena itu disarankan kepada perusahaan PT Uniliver Tbk untuk selalu memperhatikan siapa saja yang akan dijadikan seorang Endorser selanjutnya demi keberhasilan suatu produk Clear Shampo di Indonesia.

Hasil penelitian ini menunjukan bahwa Brand Image berpengaruh positif terhadap keputusan pembelian, Oleh karena itu disarankan kepada perusahaan PT Uniliver Tbk di harapkan dapat terus berinovasi dalam menciptakan varian baru yang menjaga kualitas produk Shampo Clear untuk mempertahankan citra merek karena komponen tersebut menjadi salah satu patokan bagi konsumen dalam memutuskan pembelian.

Hasil penelitian ini menunjukan bahwa Celebrity Endorser dan Brand Image secara bersama-sama berpengaruh positif terhadap keputusan pembelian.Oleh karena itu perusahaan maupun pimpinan yang terkait bisa meningkatkan dan memperhatikan penggunaan Celebrity Endorser selanjutnya dan Mempertahankan Citra merek dari Shampo Clear demi keberhasilan produk tersebut.

\section{Daftar Pustaka}

Bimal Anjum, Dr, Sukhwinder Kaur Dhanda and Sumeet Nagra. 2012. Impact of Celebrity Endorsed Advertisiments on Consumers. Asia Pacific Journal of Marketing \& Management Review. 1 (2): h: 22-33

Dinny Puspita Sari dan Edin S. Djatikusuma, 2012. Pengaruh Celebrity Endorser Ayu Ting-ting dalam Iklan Televisi terhadap Brand Image Produk Mie Sarimi. Jurnal Manajemen dan Kewirausahaan, 2(4): h: 1-9

Emmy Supariyani, Hj, Jan Horas V Purba dan M. Rangga, 2006. Pengaruh endorser pada media iklan televisi terhadap Citra Produk. Jurnal Ekonomi dan Bisnis. 6(2): h:99-103

Endang Sulistya Rini dan Dina Widya Astuti, 2012. Pengaruh Agnes Monica sebagai Celebrity Endorser terhadap pembentukan brand image Honda Vario. Jurnal Bisnis dan Manajemen. 6(1): h: 1-12

Parengkuan, V., Tumbel, A., \& Wenas, R. (2014). Analisis Pengaruh Brand Image dan Celebrity Endorsment Terhadap Keputusan Pembelian Produk Shampo Head And Shoulders Di 24 Mart Manado. Jurnal EMBA Vol.2 No.3 September 2014, Hal. 1792-1802.

Shimp, Terence, A. 2003. Periklanan, Promo, Aspek Tambahan Komunikasi Pemasaran Terpadu (diterjemahkan oleh Revyani Sjahrialdan Dyah). Edisi Kelima. Jakarta: Airlangga. 
Schiffman \& Kanuk. 200). Perilaku Konsumen. Edisi Tujuh. Jakarta: Prentice Hall

Wulandari, Ni Made R. dan Nurcahya, I Ketut. 2015. Pengaruh Celebrity Endorser, Brand Image, Brand Trust Terhadap Keputusan Pembelian Clear Shampoo di Kota Denpasar. E-Jurnal Manajemen Unud, Vol. 4, No.11, 2015: 3909-3935

Setiadi, Nugroho J. (2003). Perilaku Konsumen. Kencana. Jakarta. 